\title{
SET Domain
}

National Cancer Institute

\section{Source}

National Cancer Institute. SET Domain. NCI Thesaurus. Code C14093.

SET domains appear to be protein-protein interaction domains. SET domains mediate interactions with a family of proteins that display similarity with dual-specificity phosphatases (dsPT Pases). The SET domain genes are widely represented in the eukaryotic genomes. Proteins bearing the widely distributed SET domain (ca. 130 amino acid) contribute to epigenetic mechanisms of gene regulation by methylation of lysine residues in histones and other proteins. The SET domain appears generally as one part of a larger multidomain protein. It appears that the varied domains that occur together with the SET domain are involved in recognizing protein substrates and "reading" histone tails in order to dictate which (if any) of their multiple lysine residues should get methylated. (From Pfam PF00856) 